\title{
Mulheres transexuais e travestis negras: vulnerabilidade, preconceito e discriminação
}

\author{
Gabriel Castro Siqueira*
}

Alice Marrone Marcolino*

Alessandro de Oliveira dos Santos ${ }^{* *}$

\footnotetext{
* Doutorando em Psicologia Social na Universidade de Sáo Paulo, Mestre em Psicologia Social pela mesma instituição. Email: gabrielcs@usp.br. https://orcid.org/0000-0003-4107-3276

** Formada em psicologia pela Universidade de São Paulo. Email: alice.marcone@gmail.com. https:// orcid.org/0000-0002-8773-9419

${ }^{* * *}$ Docente do Instituto de Psicologia da Universidade de São Paulo. Email: alos@usp.br. https:// orcid.org/0000-0002-5261-0332

Fecha de recepción: 01/06/2020. Fecha de aceptación: 30/06/2021.
} 


\title{
Mulheres transexuais e travestis negras: vulnerabilidade, preconceito e discriminaçáo
}

\section{Resumo}

Este texto discute experiências de preconceito e discriminação de mulheres transexuais e travestis negras e suas estratégias de enfrentamento. Trata-se de um estudo qualitativo descritivo, com cinco participantes na faixa etária de 25 até 47 anos. Os resultados mostraram que a maior vulnerabilidade à violência de mulheres transexuais e travestis negras resulta de experiências de preconceito e discriminação racial e sexual, fazendo com que elas se sintam prejudicadas ao realizar sua transiçáo de gênero e impedidas de viver plenamente as identidades que assumiram para si. O pertencimento religioso e a participação em coletivos auto-organizados são suas principais estratégias de enfrentamento para fortalecer a autoestima, elaborar as experiências de preconceito e discriminação e explorar suas possibilidades de feminilidade livremente. A criação ou aprimoramento de políticas que possam apoiar integralmente à saúde das mulheres transexuais e travestis, é fundamental para promover o bem viver dessa população e reduzir sua vulnerabilidade à violência.

Palavras-chave: transgênero, negros, vulnerabilidade, preconceito, discriminação.

\section{Black travestis and trans women: Vulnerability, prejudice, and discrimination}

\begin{abstract}
This article discusses experiences of prejudice and discrimination of black travestis and trans women and their coping strategies. This descriptive qualitative study examined the experiences of five participants in the age range of 25 to 47 years, living in Brazil. The findings suggest that black travestis and trans women experience high levels of vulnerability to violence due to perceived racial, sexual, and gender prejudice and discrimination. That often hinders their gender transition processes and disturbs their flourishing in their diversified identities. Religious belonging and participation in social movements are their main coping strategies to strengthen self-esteem, elaborate experiences of prejudice and discrimination, and explore their possibilities of womanhood or femininity. The creation or improvement of healthcare policies and practices designed with and for travestis and trans women is fundamental to their good living and to reduce their vulnerability to violence.
\end{abstract}

Keywords: Black trans women, transgender, vulnerability, prejudice, discrimination.

\section{Mujeres trans y travestis negras: vulnerabilidad, prejuicio y discriminación}

\section{RESUMEN}

Este artículo analiza experiencias de prejuicio y discriminación de mujeres trans y travestis negras y sus estrategias de afrontamiento. Se trata de un estudio cualitativo descriptivo con cinco participantes de entre 25 y 47 ańos que viven en Brasil. Los resultados sugieren que mujeres trans y travestis negras experimentan altos niveles de vulnerabilidad a la violencia debido a prejuicios y discriminación racial, sexual y de género. Esto interfiere en sus procesos de transición de género y perturba su florecimiento en sus identidades diversificadas. La pertenencia religiosa y la participación en los movimientos sociales son sus principales estrategias de afrontamiento para reforzar la autoestima, elaborar las experiencias de prejuicio y discriminación, y explorar sus posibilidades de feminidad. La creación o mejora de políticas y prácticas de salud diseñadas con y para las mujeres trans y travestis es fundamental para su buen vivir y para reducir su vulnerabilidad a la violencia.

Palabras clave: mujeres trans negras, transgénero, vulnerabilidad, prejuicios, discriminación. 


\section{INTRODUÇÃo}

A violência enquanto fenômeno múltiplo e complexo que atinge as mulheres brasileiras, se expressa cotidianamente de maneira desigual entre os diferentes segmentos femininos que compóem essa população, revelando a sobreposição de marcadores sociais como raça, orientação sexual e classe social. As mulheres negras, por exemplo, integram um segmento feminino especialmente vulnerável à violência no país. Segundo dados do Dossiê Violência Contra Mulheres do Instituto Patrícia Galvão (2015), referentes ao ano de 2013, dentre as mulheres vítimas de violência $59,4 \%$ eram negras. Já dentre as vítimas de homicídio $62,2 \%$ eram mulheres negras. Além disso, em 2013, enquanto a taxa de homicídio de mulheres brancas diminuiu 9,8\%, a taxa de homicídio de mulheres negras aumentou 54,2\%.

No Brasil, as mulheres transexuais e travestis, em especial as negras, encontram-se numa perigosa intersecção de opressóes de raça, orientaçáo sexual e classe social que aumentam sua vulnerabilidade à violência. Segundo a Associação Brasileira de Lésbicas, Gays, Bissexuais, Travestis e Transexuais (ABGLT, 2019) 18 milhóes de pessoas LGBT vivem no país. Apesar de não haver dados oficiais do governo sobre a população de travestis e transexuais, segundo a Associação Nacional de Transexuais e Travestis (ANTRA, 2019), estima-se que 1,9\% da população brasileira seja nãocisgênero. Dados da Rede Nacional de Pessoas Trans do Brasil (2019), por sua vez, mostram que $90 \%$ das mulheres transexuais e travestis exercem a atividade de prostituição e tem uma expectativa de vida de 35 anos.

No Brasil, os dados e informaçóes sobre as mulheres transexuais e travestis são escassos, em especial sobre as negras. Entretanto, dados obtidos por O'Hara (2014) mostram que em termos globais, as transexuais e travestis negras são as que mais sofrem violência e as principais vítimas de assassinato. Utilizando dados e informaçóes de sítios eletrônicos como o "Transrespect versus Transphobia" (https:// transrespect.org/en/) e o "Transgender Day of Remembrance" (https://tdor.info/), O'Hara (2014) constatou que das 826 mulheres transexuais assassinadas entre 2000 e 2014, a maioria era de mulheres negras e pobres. Elas enfrentam mais riscos de sofrer crime de ódio e violência policial e seus familiares e amigos têm menor possibilidade de obter informação e requerer justiça em relação ao ocorrido com elas (O’Hara, 2014). Segundo dados do sítio eletrônico “Transgender Europe”(2020) o Brasil é o país que mais mata pessoas transgênero no mundo (https://tgeu. org/). Tais mortes, em geral, contém requintes de crueldade envolvendo estupro, empalhamento e mutilaçóes. Segundo a ANTRA (2019), 124 pessoas transgênero morreram assassinadas no Brasil no ano de 2019, sendo 67\% profissionais do sexo.

Contextos sociais que interseccionam opressóes de raça, orientação sexual e classe social de pessoas e/ou grupos favorecem a negligência ou violação de direitos 
básicos como o direito à vida, saúde e educação, ampliando a vulnerabilidade ao adoecimento, à marginalização e à violência (Santos \& Paiva, 2007).

O conceito de vulnerabilidade foi utilizado pela primeira vez na área de advocacia internacional em referência a pessoas ou grupos fragilizados na garantia de seus direitos. A partir da década de 1990 foi incorporado pela área da saúde na tentativa de compreender as tendências mundiais da epidemia de Aids. Como afirmam Paiva, Ayres, Capriati, Amuchastégui e Pecheny (2018), a maior ou menor exposição aos agravos à saúde, à marginalização e à violência resulta de um conjunto de aspectos individuais, sociais e programáticos. Por isso a compreensão da vulnerabilidade de pessoas e/ou grupos envolve sempre três níveis, individual, social e programático, e suas interaçóes, de modo a superar a dicotomia entre individual e coletivo.

O nível individual da vulnerabilidade corresponde aos aspectos físicos e psicológicos, as vivências e valores e as formas pessoais de absorver informaçóes, lidar com as circunstâncias e adotar comportamentos. O nível social, por sua vez, refere-se às condiçóes de inserção na sociedade que favorecem ou não a suscetibilidade de pessoas e/ou grupos a determinado agravo à saúde, à marginalização e à violência como, por exemplo, a raça, a orientação sexual, a escolarizaçáo, e as possibilidades de renda e de consumo. O nível programático, por fim, refere-se às relações entre as pessoas e/ou grupos e as políticas, instituiçóes e serviços de enfrentamento de determinado agravo à saúde ou processo de marginalização e formas de violência, como, por exemplo: a proposição de leis e a estruturação de serviços de proteção de direitos; a oferta de assistência e tratamento em saúde; a realização de programas de prevenção do adoecimento (Prestes \& Paiva, 2016).

Assim como em outras partes do mundo, no Brasil a maior vulnerabilidade à violência de mulheres transexuais e travestis negras resulta de experiências de preconceito e discriminaçấo racial e sexual. O preconceito refere-se às concepçóes, atitudes e juízos preconcebidos a respeito de pessoas ou grupos e que não são facilmente modificáveis por apresentação de evidência contrária. A discriminação, por sua vez, diz respeito a toda distinção de tratamento, exclusão ou restrição de circulaçáo de pessoas ou grupos capaz de pôr em risco as liberdades e os direitos em quaisquer esferas (Santos, 2012).

Embora exista uma ampla literatura sobre preconceito e discriminaçẫo de mulheres negras cisgênero permanece uma lacuna no que diz respeito às mulheres transexuais e travestis negras. Neste estudo focalizamos as experiências de preconceito e discriminação e as estratégias de enfrentamento de mulheres transexuais e travestis negras da cidade de São Paulo, visando contribuir para a ampliação do repertório de saberes e práticas para enfrentamento desses fenômenos.

O estudo integra uma pesquisa maior realizada entre 2016 e 2018 sobre a exposição e envolvimento de mulheres negras, no Brasil e nos Estados Unidos, com 
a violência e suas estratégias de luta por justiça e reconhecimento (Smith, Bento, Paiva \& Santos, 2018). Desse modo, apresentamos uma análise de conteúdo de entrevistas com mulheres transexuais e travestis negras e fazemos recomendaçóes para futuras pesquisas e açóes profissionais na área da saúde, com base nas vivências compartilhadas nas entrevistas.

\section{Método}

Trata-se de um estudo qualitativo descritivo com base em entrevistas com 05 mulheres transexuais e travestis negras, na faixa etária entre 25 e 47 anos, que vivem na cidade de São Paulo. As entrevistadas foram selecionadas com base em sua autoidentificação como mulher e seu fenótipo, ou seja, a cor de pele negra. Os nomes delas não foram identificados, sendo substituídos por nomes fictícios. Dentre as 28 mulheres convidadas para entrevista, por meio de contato telefônico, mensagem eletrônica ou abordagem direta, somente 05 aceitaram participar. O que revela a dificuldade em acessar essa população, dada sua desconfiança em relação aos benefícios que as pesquisas científicas têm trazido para ela. O quadro I contém informaçóes sobre o perfil das entrevistadas:

Quadro 1. Perfil das entrevistadas (2018)

\begin{tabular}{llllll}
\hline Nome & Idade & Gênero & Escolaridade & Profissão & Religião \\
\hline Paula & 27 & Travesti & Ensino médio técnico & Telemarketing & Umbanda \\
Kelly & 25 & Travesti & Ensino fundamental & Modelo & Sem religião \\
Solange & 47 & Mulher & Ensino superior & Secretaria & Sem religião \\
Nubya & 25 & Travesti & Ensino médio & Artista & Espírita \\
Micheli & 25 & Mulher & Ensino superior & Cantora & Candomblé \\
\hline
\end{tabular}

As entrevistas foram realizadas ao longo do ano de 2017, mediante assinatura de Termo de Consentimento Livre e Esclarecido (TCLE) pelas participantes ${ }^{1}$. Duraram em média 40 minutos e tiveram como fio condutor um roteiro semiestruturado de perguntas sobre concepçôes de ser mulher e mulher negra, episódios de preconceito e discriminaçáo e estratégias de enfrentamento desses fenômenos.

Após a transcrição das entrevistas gravadas em áudio o material foi submetido à análise de conteúdo, buscando-se reconhecer os significados emergentes nos relatos. Posteriormente, conforme proposto por Puglisi e Franco (2005) houve a descrição

\footnotetext{
1 Como mencionado anteriormente, este estudo integra uma pesquisa maior, aprovada junto ao Comitê de Ética de Pesquisa do Instituto de Psicologia da USP com Certificado de Apresentaçáo de Apreciação Ética (CAAE) número: 62602716.9.0000.5561.
} 
dos aspectos que apareceram de forma recorrente e o agrupamento dos principais significados emergentes em 03 categorias: (a) concepçóes sobre ser mulher e ser mulher negra; (b) experiências de preconceito e discriminação; (c) estratégias de enfrentamento do preconceito e da discriminação. A construção das categorias foi feita com base nas similaridades temáticas presentes nos relatos das entrevistadas de modo a permitir agrupamentos homogêneos.

\section{Resultados}

\section{- Concepçóes sobre ser mulher e ser mulher negra}

No que se refere às concepçóes sobre ser mulher, os relatos das entrevistadas giraram em torno de questóes referentes ao "tornar-se mulher", enquanto um ato de coragem de assumir para si e para a sociedade sua feminilidade. Tal ato de coragem apareceu com mais frequência nos relatos das entrevistadas que se autoidentificaram como travestis.

A entrevistada Solange contou que se percebeu mulher pela primeira vez quando tinha 02 anos de idade. Mas, que "[...] tem só 03 anos que eu estou plena e transicionada”. Para Kelly, Nubya e Paula, por sua vez, ser mulher foi um processo. Em suas palavras:

"[...] eu me tornei uma mulher porque eu passei por um monte de processos, com o meu corpo com a minha realidade, e eu acho que ser mulher é ter a paciência de assumir tudo que eu tinha que fazer e a coragem de ser" (Kelly, 25 anos).

"[...] eu nunca me senti outra coisa, eu acho que passei por muitos processos, mas eu sempre me senti desta forma [...]" (Nubya, 25 anos).

"[...] como todo mundo dizia que eu tinha que ser um menino o que eu fiz foi falar para mim que eu era eu [...]. Até que eu consegui me desvencilhar desse negócio do não pode e consegui me assumir como mulher para mim mesma" (Paula, 27 anos).

Já para Micheli, ser mulher emergiu associado a uma condição de desvantagem, de estar em último lugar em relação a alguma coisa. Aqui a vulnerabilidade social e programática aparece na fragilização percebida por ela de que ser mulher está de alguma forma associada à desvantagens. Em suas palavras:

“[...] Ser mulher para mim é, em primeiro lugar, você saber que você está na linha de trás [...] na fila de quem vai receber alguma coisa no final, você está sempre por último, porque sempre fui a última" (Micheli, 25 anos). 
Para a maioria das entrevistadas as concepçóes de ser mulher e ser mulher negra não podem ser separadas, na medida em que em ambas está presente uma noção de coragem, força e autonomia como exemplificado pelos relatos de Micheli e Paula:

“[...] ser mulher preta é ser independente, ser forte, ser dona de si, não dá para a gente depender de boy, não dá para gente depender de amigo, não dá para a gente depender de mulher branca [...]" (Micheli, 25 anos).

"Eu acho que primeiramente é saber que onde eu estou hoje não dependeu de ninguém além de mim mesma [...]” (Paula, 27 anos)

Por outro lado, as entrevistadas repeliram a associação direta entre ser mulher e as experiências de preconceito e discriminação, como diz Nubya: "[...] isso para mim, não significa ser mulher, ser o alvo desta violência, entendeu”.

Existem diversas maneiras de ser mulher, e desconsiderar isso nivelaria as especificidades das mulheres transexuais e travestis igualando suas experiências, de modo superficial, as experiências das mulheres cisgênero. No relato de Nubya, por exemplo, destaca-se sua preferência em construir uma feminilidade como travesti.

A identidade de travesti tem sido ressignificada desde os anos 2000, principalmente por jovens periféricas que buscam uma identidade para além das classificaçóes binárias ou burguesas de sua condição transgênero. No relato de Nubya, isso fica evidente.

"Tudo que eu vou falar diz respeito a mim mesma, como uma travesti mesmo, preta. Eu me identifico como uma travesti [...] eu sempre fui feminina, minha experiência sempre foi ser preta, bicha, travesti, mulher. [...] Hoje em dia, eu passo um batom, coloco um vestido e vou ao mercado como qualquer mulher cis[gênero], não preciso justificar para ninguém o que eu sou. Ser travesti para mim é isso também, é ser livre" (Nubya, 25 anos).

A ressignificação do termo travesti também é defendida pelo movimento transfeminista ao reconhecer a legitimidade das expressóes, existências e corpos das pessoas trans (Jesus, 2012). Segundo Moira (2017), os termos «travesti» e «mulher trans» são sinônimos, embora não signifiquem a mesma coisa. Cada termo tem sua história que ao ser acionada, ativa diferentes sentidos e revela propósitos distintos.

\section{- Experiências de preconceito e discriminação}

Os relatos das entrevistadas acerca de suas experiências de preconceito e discriminação mostraram a rejeição e impedimentos associados, por um lado, as situaçôes de vulnerabilidade social e programática das pessoas transgênero e, por outro, as situaçóes de vulnerabilidade social e programática das pessoas de raça negra. A combinação entre experiências de preconceito e discriminação racial e 
sexual se manifesta no impedimento da realização dos potenciais de vida dessas mulheres, no agravamento de sua saúde física e mental e na violação de seus direitos.

A maioria das entrevistadas relatou algum episódio no qual passaram por impedimentos na vida cotidiana, sobretudo no mercado de trabalho, como exemplificado pelos relatos de Paula, Nubya e Kelly:

"Eu sinto que ser preta é ser sempre preterida em todos os espaços [...] no mercado de trabalho, eu sinto que para gente é muito complicado não importa se você está com uma boa maquiagem, se você está bem-vestida, você é sempre rejeitada no mercado de trabalho" (Paula, 27 anos).

"[...] no ponto [de prostituição] eu percebo o racismo, muitas vezes todas vão e eu fico, eu percebo muito isso, a forma como uma travesti ou uma mulher trans branca é tratada é com mais gentileza do que da forma que eu sou tratada" (Nubya, 25 anos).

"Quando eu trabalhava de garçonete num restaurante, toda semana tinha pelo menos uma família que pedia para outra pessoa atendê-los que não fosse eu. Eu acredito que uma travesti branca, uma trans branca, no mercado de trabalho, pode ser até que ela náo tenha tanto respeito, mas essas deselegâncias talvez sejam menores" (Kelly, 25 anos).

Para Nubya e Kelly as experiências de preconceito e discriminação vividas talvez fossem menores para uma mulher transexual branca. Kelly aponta ainda que é mais frequente que uma mulher transexual negra seja alvo de acusaçóes. Em suas palavras: "Quem roubou isso? Quem roubou o marido? A preta” (Kelly, 25 anos).

Solange também relatou ocasióes em que se sentiu preterida no mercado de trabalho. Segundo ela ao procurar trabalho não foi contratada por ser «assim demais». Ela contou que só conseguiu ser contratada quando percebeu que «não tinha outro jeito, eu teria que fazer o papel de homem» (Solange, 47 anos).

Nos relatos das entrevistadas, foi possível perceber ainda impedimentos para realizar o processo de transiçẫo de gênero. Esses impedimentos revelam a vulnerabilidade programática das mulheres transexuais e travestis que se expressa pela falta de políticas públicas de geração de renda, assistência e saúde para essa populaçáo, como mostram os relatos de Kelly e Paula:

"Ainda não tenho estrutura financeira. Eu só serei capaz de fazer essa transição [de gênero] quando tiver alguma estabilidade financeira. Eu queria muito isso. Está prejudicando minha autoestima" (Kelly, 25 anos).

"Eu não estou disposta a ir a um psiquiatra, psicólogo, é muito louco que o Estado obrigue a passar por estes caras para conseguir medicação [para transição de gênero] [...]» (Paula, 27 anos). 
As entrevistadas não indicaram um modo singular de viver a transição, mas todas têm em comum o fato de evitarem o aparato médico, psiquiátrico e psicológico. O despreparo dos profissionais de saúde para lidar com essa população aumenta o receio delas de sofrer violência. Em pesquisa realizada por Bonassi, Amaral, Toneli \& Queiroz (2015) com 100 pessoas travestis e transexuais, constatou-se que 40\% delas sofreram algum tipo de violência por parte dos agentes de serviços públicos de saúde.

Os relatos a seguir indicam que as experiências de preconceito e discriminação fazem parte do cotidiano das mulheres negras transexuais e travestis, desde a infância até a vida adulta, exemplificando a vulnerabilidade individual presente nos contextos de interação:

"Na infância, meus pais ignoravam que eu era uma criança que a sociedade costumava dizer que era afeminada. Meu pai me batia muito, minha máe também. Eu era muito silenciada na infância. Às vezes eu era espancada e nem sabia por que eu estava apanhando" (Kelly, 25 anos).

"[...] eu náo podia ser eu, a mulher, mas eu podia ser o viadinho, femininho que é abusado que apanha dos outros de graça [...] parecia que eu tinha um para-raios em mim" (Micheli, 25 anos).

As entrevistadas também trouxeram relatos de violência policial. Solange contou sobre a Operação Tarântula, realizada na cidade de São Paulo durante o período de ditadura no Brasil:

"Ir para o centro de Sáo Paulo tinha se tornado uma coisa muito perigosa [...] porque a Operaçáo Tarântula tinha começado, ou Operaçáo Arrastáo, que era um extermínio de homossexuais afeminados e pobres que ficavam nas ruas. Travestis e mulheres trans, como a gente não tinha acesso às boates, a gente ficava na rua" (Solange, 47 anos).

Solange contou que uma vez viu uma travesti negra ser assassinada por um policial. Em suas palavras:

'Nós estávamos apavoradas. O polícia disse: 'Qual o problema, nunca viram sangue escorrer? Corram enquanto vocês podem!'” (Solange, 47 anos).

Kelly e Nubya também contaram episódios de violência policial que viveram. Nas palavras delas:

"Eu tenho muito medo da polícia. Muito, muito medo [...]. Eu já apanhei deles [...]. Foi humilhante [...]. Um cara me pegou no ponto [de prostituiçăo]. Eu fiz o serviço no carro e entáo ele náo queria me pagar o que a gente tinha combinado. Eu disse que era $R \$ 50,00$ e ele queria me pagar $R \$ 20,00$. Daí a gente estava 
brigando e a polícia veio. Eu apanhei [...]. Fui embora sem nenhum dinheiro, sem meus R\$20,00, e humilhada” (Kelly, 25 anos).

"Eu percebo muito isso, de já ter apanhado da polícia na frente das outras meninas e eu ser a única preta e a única que apanhou" (Nubya, 25 anos).

No caso das trabalhadoras do sexo, a violência física cometida por policiais é uma constante (Busin, 2015). Segundo Moira (2017), "essa é uma profissão que se exerce no anonimato, em meio à vergonha e ao medo; então, é difícil que uma profissional que esteja enfrentando dificuldades ou violência saiba com quem contar" (p. 365).

A ausência de igualdade de direitos, a moral sexual rígida, as relaçóes de raça e gênero opressoras, a pobreza e a falta de políticas públicas produzem, em conjunto, o aumento da vulnerabilidade social e programática das mulheres transexuais e travestis à violência. Como exemplificam os cenários de violência doméstica relatados pelas entrevistadas, que frequentemente rompem relaçóes familiares e expóem pessoas transgênero a vida em situação de rua, ou ainda pelas dificuldades dos serviços de saúde no que se refere ao acolhimento e aos procedimentos para transição de gênero (ANTRA, 2019).

\section{- Estratégias de enfrentamento de preconceito e discriminação}

$\mathrm{O}$ preconceito e a discriminação vivenciados pelas mulheres transexuais e travestis geram sofrimento e produzem prejuízos que vão desde a baixa autoestima, até a narcotização, os transtornos psiquiátricos e o suicídio, afetando as possibilidades de bem viver dessa população (Jesus, 2016).

Nas entrevistas foi possível constatar algumas tendências referentes às estratégias de enfrentamento frente ao preconceito e discriminação. Primeiramente, aparece a tentativa de tomar em consideração esses fenômenos como problemas sociais e não fruto de atributos pessoais como exemplificado pelo relato de Paula:

"Eu não sei se existe uma fórmula, porque existe um genocídio da população trans preta que acontece devido ao genocídio racial. Eu penso que existem medidas que deveriam ser tomadas, medidas sérias, mas é uma coisa tão complexa, mas eu acredito que o acesso à educação é o que tem que acontecer” (Paula, 27 anos).

Já Kelly trouxe a arte como "válvula de escape para a realidade tão dura" e como lugar onde consegue elaborar sua vivência enquanto travesti negra na cidade de São Paulo. A entrevistada Solange, por sua vez, tem grande paixão pela moda e aponta isso como uma maneira de reinventar sua estética. Paula e Micheli também mencionaram a importância do pertencimento religioso como suporte social para lidar com as tensóes presentes em seu cotidiano. Nas palavras de Paula: 
“[...] a religião para mim é tudo, tanto que para mim eu tenho uma relação com as minhas religióes desde sempre, desde muito pequena. Por conta da minha espiritualidade mesmo, [...]. A minha espiritualidade nunca me deixou cair, é o que me segura, o que me dá forças para continuar" (Paula, 27 anos)

Uma estratégia de enfrentamento coletiva do preconceito e discriminação que foi mencionada com frequência pelas entrevistadas diz respeito à articulação em prol da despatologização da transgeneridade. Como mencionado anteriormente, cada entrevistada apresenta um modo singular de viver sua transição, mas todas têm em comum o fato de evitarem os aparatos médicos e psiquiátricos para regulá-la.

Nesse sentido, os relatos apontam para uma fluidez de experiências em relação à feminilidade e a tentativa contínua de desconstrução do binarismo de gênero, mostrando que a plenitude de uma pessoa transgênero náo está atrelada somente a um processo de hormonização e a utilização de recursos médicos e cirúrgicos, que reiteram o mito da "transexual verdadeira", construído pelos discursos médicos e legais.

Solange, por exemplo, contou que nunca precisou de hormônios para se sentir mulher, e quando tentou realizar a terapia hormonal ficou extremamente incomodada com os efeitos químicos dos remédios. Ela realiza sua transição de outros modos, reiterando a autonomia enquanto pessoa para determinar sua identidade e seu corpo (cabelo longo, prótese nos seios, roupas). Solange entrou com um processo judicial para mudar seu nome e gênero sem a necessidade de laudos ou cirurgias. Com este ato, ela rejeita completamente o enquadre psicopatológico de sua identidade, afirmando a legitimidade de ser "uma mulher com pênis".

Paula, por sua vez, fez questão de enaltecer que quer ser reconhecida como travesti e que não almeja a "passabilidade cis", isto é, ser confundida com uma mulher cisgênero, como algumas mulheres transexuais almejam. Embora não queira ser confundida com uma mulher cis, ela não abre mão de se relacionar com signos de feminilidade, tais como o cabelo comprido, o uso de sapato alto e de maquiagem.

Um aspecto que ficou explícito nos relatos e que chamou atenção foi o fato dessas mulheres transexuais e travestis negras encontrarem-se articuladas seja através de redes sociais, movimentos ou locais de resistência como, por exemplo, o Aparelha Luzia, que busca se constituir como espaço em Sáo Paulo promotor de eventos culturais com protagonismo de mulheres transexuais e travestis negras e debates sobre questóes referentes à luta contra o racismo e a transfobia. Espaços coletivos de auto-organização como este servem para ampliar a autoestima, quebrar os silêncios e elaborar vivências de sofrimento e violência. Nas palavras de Micheli: 
"Eu como mulher trans preta tenho a possibilidade de ir num lugar [Aparelha Luzia] onde eu estou chegando, de fazer alguma coisa, falar mais, conversar com as pessoas [...] quando você é uma pessoa trans, você se cala [...]" (Micheli, 25 anos).

\section{CONSIDERAÇÓES FINAIS}

A maior vulnerabilidade à violência de mulheres transexuais e travestis negras resulta de experiências de preconceito e discriminação racial e sexual que impactam tanto no desenvolvimento emocional quanto no reconhecimento de direitos básicos e de cidadania dessas mulheres. Tais experiências são sustentadas por um conjunto de práticas culturais e institucionais da sociedade brasileira que reproduz privilégios para determinados grupos (brancos, heterossexuais e cisgêneros) e desvantagens para outros (negros, homossexuais, travestis e transexuais).

Por meio das entrevistas realizadas foi possível identificar como a intersecção de opressóes de raça, gênero, orientação sexual e classe social influenciam no agravo de situaçóes de vulnerabilidade individual (aspectos físicos e psicológicos, valores, vivências), social (raça, orientaçáo sexual, renda) e programática (políticas, instituiçóes, serviços).

No nível individual da vulnerabilidade constatou-se que as expressóes de feminilidade, incluindo a transição de gênero, embora tragam empoderamento também estão associadas a quadros de adoecimento, percebidos como ansiedade, pânico e depressão. No nível social da vulnerabilidade, por sua vez, constatou-se a violação de direitos em conflitos familiares, perseguiçôes no ambiente escolar e impedimentos no mercado de trabalho. Por fim, no nível programático da vulnerabilidade, constatou-se a ausência de políticas específicas intensificada pelo despreparo dos agentes públicos, em especial nas áreas da saúde e segurança.

Qualquer expressão de feminilidade performada por uma pessoa que nasce com um pênis tende a ser motivo para manifestação de preconceito e discriminação. A análise de conteúdo das entrevistas mostrou que a autocompreensão e expressão de suas identidades "não-inteligíveis" envolveu experiências de preconceito e discriminação no ambiente familiar, na escola, no trabalho, ou seja, manifestaçôes de hostilidade, rejeição ou exclusão.

O preconceito e a discriminação impedem a realização dos princípios de justiça e reconhecimento de mulheres negras transexuais e travestis. O princípio da justiça não é respeitado, na medida em que as mulheres vivenciam tratamento desumano ou degradante, incluindo aqueles cometidos por agentes do Estado, no caso a polícia (Zucchi, Barros, Redoschi, Deus \& Veras, 2019). Já o princípio de reconhecimento não é respeitado na medida em que não há ainda na cidade de São Paulo açôes do 
poder público com vistas à mitigação do preconceito e discriminação das mulheres negras transexuais e travestis, tampouco ações para efetivação de sua participação de forma igualitária em assuntos públicos e políticos relacionados à luta contra o racismo. Os relatos das entrevistadas mostraram que seu engajamento e participação nessa luta tem se dado a partir da auto-organização fora dos espaços de participação da sociedade civil existentes no poder público.

Os relatos das entrevistadas também mostraram como o preconceito e discriminação fazem com que elas se sintam impedidas de realizar sua transição de gênero e viver plenamente as identidades não-inteligíveis que assumiram para si.

As literaturas tradicionais da área médica, psicológica e jurídica não dão conta de respeitar essas pessoas em suas singularidades e produzem discursos que normatizam essas vivências dentro do esquema da binaridade e da cisgeneridade. Nesse sentido, é importante analisar as complexidades e ambivalências das diferentes vivências de pessoas transgênero e como elas se relacionam de modo subversivo ou reacionário às normas que regem a sexualidade e o gênero (Lanz, 2015).

O campo da saúde mental requer novas abordagens de modo a caminhar para relaçôes terapêuticas de caráter menos patologizante, inclusive para pessoas transgênero que já estejam em tratamento hormonal por conta própria por não quererem se submeter aos processos tradicionais de ter de conseguir um diagnóstico favorável. Nesse sentido, defendemos a criação ou aprimoramento de serviços de saúde, em especial de saúde mental, de apoio integral à saúde dessa população, sem a necessidade de que essa relação terapêutica tenha cunho diagnóstico ou prescritivo, como é feito atualmente no Brasil, com exigência de produção de um laudo favorável ou não ao processo de transição.

Em Março de 2018, o Supremo Tribunal Federal (STF) decidiu em favor de que as pessoas transgênero possam alterar o nome no registro civil sem a realização de cirurgia de mudança de sexo ou avaliação médica ou psicológica. No mesmo período, o Tribunal Superior Eleitoral (TSE) garantiu constitucionalmente aos candidatos transgênero o direito de usarem o nome social na urna eletrônica e de serem incluídos nas cotas, tanto masculina quanto feminina, dentro dos partidos.

A Organização Mundial da Saúde (OMS), em Junho de 2018, também deu um passo significativo rumo à despatologização da transgeneridade ao retirá-la do grupo das patologias descritas como transtornos mentais da $11^{\text {a }}$ Edição da Classificação Internacional das Doenças (CID-11). A transgeneridade passou a ser classificada como "incongruência de gênero", sendo realocada para um novo capítulo intitulado "condiçóes relativas à saúde sexual". Para Jesus (2018) embora essa mudança represente um avanço mantém o caráter de patologia da transgeneridade na medida em que a palavra «incongruência» perpetua a ideia de que gênero não é uma categoria cultural, mas diagnóstica. 
Analisando as situações de vulnerabilidade as quais são expostas mulheres transexuais e travestis negras, concluímos que as estratégias de enfrentamento através de movimentos sociais têm atingido resultados na forma de respostas políticas, como exemplificado pelo número de candidatas trans eleitas em 2018. Presenciamos também nos últimos anos o surgimento do transfeminismo (Jesus, 2016) como estratégia de enfrentamento, com uma forte presença nas mídias sociais, blogs e internet e conquistando espaço no âmbito acadêmico, através do trabalho de pessoas transgênero e pesquisadoras da temática trans. Estes movimentos têm influenciado mudanças na realidade social, exemplificadas nos fatos supracitados referentes ao STF, TSE e OMS.

As recentes mudanças apontam para um caminho que responsabiliza os profissionais e pesquisadores da área de saúde a rever os conceitos que têm orientado suas práticas e discursos em relação à populaçáo transgênero, de modo a trabalhar em favor do enfrentamento do preconceito e discriminação que acometem as mulheres transexuais e travestis e produzir saberes e práticas capazes de orientar ações do poder público em relação aos direitos e ao bem viver dessa população.

\section{REFERÊNCIAS}

Associação Brasileira de Lésbicas, Gays, Bissexuais, Travestis e Transexuais. (2019). Dossiê População LGBT+ 2019. https://www.abglt.org/teia-lgbti

Associação Nacional de Transexuais e Travestis. (2019). Dossiê dos Assassinatos e da violência contra pessoas Trans em 2019. https://antrabrasil.files.wordpress.com/2020/01/ dossic3aa-dos-assassinatos-e-da-violc3aancia-contra-pessoas-trans-em-2019.pdf

Bonassi, B. C., Amaral, M. S., Toneli, M. J. F., \& de Queiroz, M. A. (2015). Vulnerabilidades mapeadas, violências localizadas: experiências de pessoas travestis e transexuais no Brasil. Quaderns de Psicologia, 17(3), 83-98. https://doi.org/10.5565/rev/ qpsicologia. 1283

Busin, V. M. (2015). Morra para se libertar: estigmatização e violência contra travestis. Tese de Doutorado, Instituto de Psicologia, Universidade de São Paulo, São Paulo. https:// doi.org/10.11606/T.47.2015.tde-14072015-092040

Dossiê Violência Contra as Mulheres (2015). Instituto Patrícia Galvão. Disponível em http:// www.agenciapatriciagalvao.org.br/dossie/violencias/violencia-e-racismo/

Jesus, J. G. D. (2012). Orientaçôes sobre a população transgênero: conceitos e termos. Brasília: Universidade Federal de Goiás.

Jesus, J. G. D. (2016). Operadores do direito no atendimento às pessoas trans. Revista Direito e Práxis, 07(15), 537-556.

Jesus, J. G. D. (2018). OMS (finalmente!) anuncia ter retirado identidades trans de lista de transtornos mentais. https://nlucon.com/2018/06/18/oms-finalmente-anuncia-terretirado-identidades-trans-de-lista-de-transtornos-mentais/

Lanz, L. (2015). O corpo da roupa. Curitiba: Transgente. 
Moira, A. R. (2017). O cis pelo trans. Estudos Feministas, 25(1), 365-373. https://doi. org/10.1590/1806-9584.2017v25n1p365

O’hara, M. E. (2014). Negras Transgênero Enfrentam uma Epidemia de Violência e Assassinatos. Disponível em https://www.vice.com/pt_br/article/53mkdq/ negras-transgenero-enfrentam-uma-epidemia-de-violncia-e-assassinatos.

Organização Mundial da Saúde - OMS. (2018). Classificação Internacional das Doenças CID-11. https://icd.who.int/en

Paiva, V., Ayres, J. R., Capriati, A., Amuchástegui, A., \& Pecheny, M. (2018). Prevención, Promoción y Cuidado: Enfoques de vulnerabilidad y derechos humanos. Buenos Aires: Teseo.

Prestes, C. R., \& Paiva, V. S. (2016). Abordagem psicossocial e saúde de mulheres negras: vulnerabilidades, direitos e resiliência. Saúde e Sociedade, 25, 673-688. https://doi. org/10.1590/s0104-129020162901

Puglisi, M. L., \& Franco, B. (2005). Análise de Conteúdo. Brasília: Liber Livro.

Rede Nacional de Pessoas Trans do Brasil. (2019). Saúde Mental e as Pessoas Trans. http:// redetransbrasil.org.br/2020/05/21/saude-mental-das-pessoas-trans/

Santos, A. D. O. D. (2012). Superar o racismo e promover a saúde da população negra: desafios para o trabalho de prevenção ao HIV/Aids no Brasil. In Vulnerabilidade e direitos humanos: prevenção e promoção da saúde: da doença à cidadania - Livro I (pp. 145-163).

Santos, A. D. O. D., \& Paiva, V. (2007). Vulnerabilidade ao HIV: turismo e uso de álcool e outras drogas. Revista de Saúde Pública, 41, 80-86. https://doi.org/10.1590/ S0034-89102007000900013

Smith, A. C., Bento, M. A., Paiva, V., Santos, A. D. O. D. (2018). Mulheres Negras e Violência. Relatório de Pesquisa. Fundação de Amparo à Pesquisa de São Paulo, 56p. (mimeo).

Transgender Europe. (2020). Trans Murder Monitoring Project. Disponível em: https:// transrespect.org/en/trans-murder-monitoring/tmm-resources/

Zucchi, E. M., Barros, C. R. D. S., Redoschi, B. R. L., Deus, L. F. A. D., \& Veras, M. A. D. S. M. (2019). Bem-estar psicológico entre travestis e mulheres transexuais no Estado de São Paulo, Brasil. Cadernos de Saúde Pública, 35, e00064618. https://doi. org/10.1590/0102-311x00064618 